Case Report

\title{
Pleomorphic Adenoma of the External Auditory Canal: A Rare Presentation
}

\author{
Samir Jaber, ${ }^{1}$ Milan Rudic, ${ }^{1,2}$ and Ivan James Keogh ${ }^{1,2}$ \\ ${ }^{1}$ Department of Otorhinolaryngology, University Hospital Galway, ENT OPD, Galway, Ireland \\ ${ }^{2}$ Discipline of Otorhinolaryngology, National University of Ireland Galway, Galway, Ireland \\ Correspondence should be addressed to Samir Jaber; samirjaber@rcsi.ie
}

Received 29 March 2015; Accepted 17 May 2015

Academic Editor: Yorihisa Orita

Copyright (C) 2015 Samir Jaber et al. This is an open access article distributed under the Creative Commons Attribution License, which permits unrestricted use, distribution, and reproduction in any medium, provided the original work is properly cited.

A 55-year-old male presented with a nine-month history of gradually enlarging, painless mass in the right external auditory canal associated with hearing loss and occasional bleeding. Examination demonstrated complete obstruction of the outer $1 / 3$ of the external auditory canal by a firm, pink, rubbery mass. CT scan of the temporal bone showed tumor mass with no evidence of bone destruction. The tumor was excised and histopathology confirmed a diagnosis of ceruminous pleomorphic adenoma of the external auditory canal. Six months following the surgery, patient is free of any recurrent disease.

\section{Introduction}

Pleomorphic adenoma (PA) is the most common benign tumor of the parotid glands, accounting for $80 \%$ of all parotid neoplasms [1]. It is a slowly growing tumor [2], lobular, not well encapsulated, and with recurrence rate of $1-5 \%$ after appropriate excision [1]. PA of the external auditory canal (EAC) is extremely rare and belongs to a group of benign and malignant tumors of the EAC, derived from the ceruminous glands [3]. Approximately 5\% of all external ear neoplasms are benign adenomas [4]. We report a case of pleomorphic adenoma of the external auditory canal in a 55-year-old male patient and discuss its clinical presentation, diagnosis, and treatment options.

\section{Case Report}

A 55-year-old male patient was seen in ENT outpatients with a growth in the right external auditory canal. The growth was painless but increased in size over a period of nine months, causing hearing loss and occasional bleeding from the canal. On examination the patient had a pink, rubbery mass obstructing the lateral $1 / 3$ of the external auditory canal. Tympanic membrane was intact and other ENT findings were normal. The patient underwent a CT scan of the temporal bone that showed $1 \mathrm{~cm}$ polypoid soft tissue growth in the external auditory canal with no underlying exostosis, osteoma, or erosion (Figure 1). Middle and inner ear structures appeared normal. Under general anesthesia the patient underwent a wide local excision of the tumor via a retroauricular approach. The tumor was attached to the skin of the external auditory canal and was removed with overlying skin. Exposed bone was covered with split thickness skin grafts and supported with silastic tubing and BIPP gauze dressings. Postoperative recovery was uneventful. Histopathology confirmed the tumor as a polypoid lesion covered by squamous mucosa, with variably sized mucin producing glands, embedded in myxofibrous stroma (Figure 2). The mucins producing glands demonstrated no features of any atypia or mitotic activity and were lined by cuboidal cells (Figure 3). Further immunohistochemistry demonstrated strong immunoreactivity of the glands in keeping with glandular/ductal differentiation. The final diagnosis was pleomorphic adenoma of the external auditory canal. Six months following the surgery there is no sign of any tumor recurrence and external auditory canal is fully healed.

\section{Discussion}

Pleomorphic adenomas are the most common salivary gland tumors [5]. Primary site is the parotid gland, $85 \%[1,6$, 7]. Though pleomorphic adenomas of the external auditory 


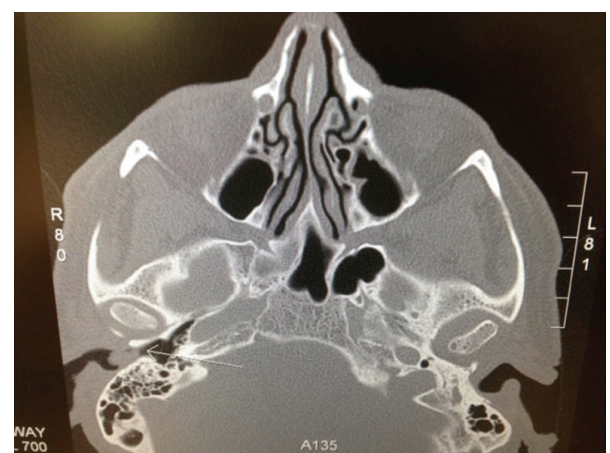

FIgURE 1: CT scan of the temporal bones, axial view, showing $1 \mathrm{~cm}$ polypoid soft tissue mass (arrow) in the external auditory canal, with no underlying exostosis or osteoma identified.

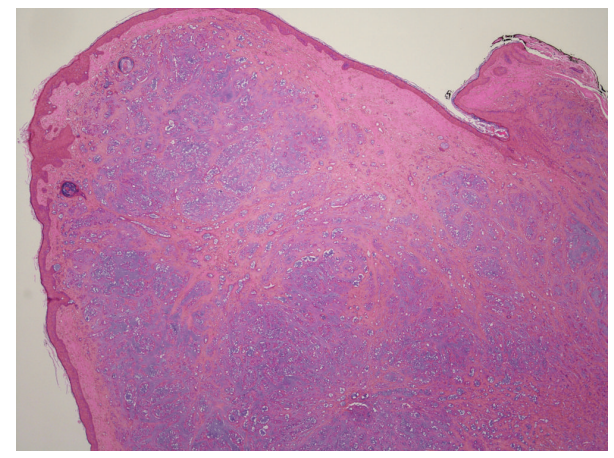

Figure 2: Histology showing polypoidal lesion covered by squamous mucosa $(\mathrm{H} \& \mathrm{E}, \times 100)$.

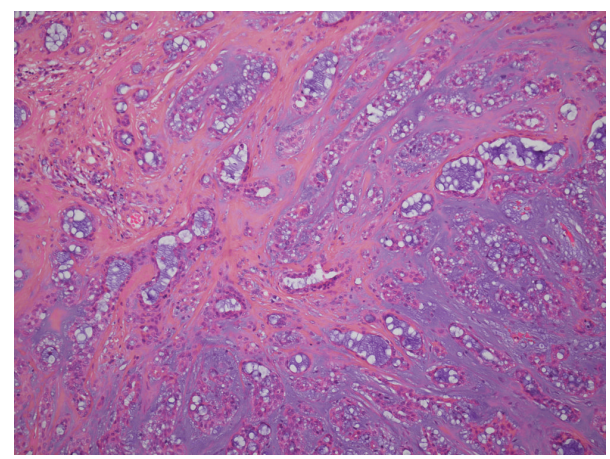

FIGURE 3: Histology showing variably sized glands, embedded into myxofibrous stroma. The glands show some mucin production $(\mathrm{H} \& \mathrm{E}, \times 200)$.

canal are extremely rare, they can arise from the ceruminous glands, which are located in the outer $1 / 3$ of the external auditory canal $[8,9]$. They can also arise from ectopic salivary gland tissue or extension of parotid pleomorphic adenoma into the ear through foramen of Huschke $[10,11]$. The external auditory canal consists of fibrous stroma covered by squamous epithelium. The outer one-third of the auditory canal contains ceruminous and sebaceous glands, which are absent in the inner two-thirds of the ear canal and the middle ear. Primary tumors of the external auditory meatus are very rare; they grow slowly and affect both sexes equally with median age of 50 years [12]. Five percent of these tumors are ceruminous (modified sweat) gland tumors [3]. Benign ceruminous gland tumors include adenoma, chondroid syringoma (pleomorphic adenoma), and syringocystadenoma papilliferum, while malignant ceruminous gland tumors include adenocarcinoma, adenoid cystic carcinoma, and mucoepidermoid carcinoma [10, 13]. Chondroid syringoma is the term that describes pleomorphic adenoma arising from skin appendages. They are characterized by the presence of subepithelial proliferation of glandular structures with nets of myoepithelial components in a chondromyxoid stroma [14, 15]. Myoepithelial cells of the ceruminous glands are precursor of primary pleomorphic adenoma of the external ear canal. Cerumen pigment and immunohistochemistry with CK7 can help to distinguish this tumor from other neoplasms [10]. Although transformation of these tumors into malignancy is rare, there is a reported case of pleomorphic adenoma of the external auditory canal alteration into aggressive chondroid syringoma $[15,16]$. These tumors should be considered as part of the differential diagnosis of any painless mass of the external auditory canal.

Current management of pleomorphic adenoma of the external auditory canal is complete surgical excision with adequate margins [17]. Recurrence is rare; however long-term follow-up is recommended [11].

In this case the tumor was completely excised surgically, and six months post-op there are no signs of recurrence.

\section{Conflict of Interests}

The authors declare that there is no conflict of interests regarding the publication of this paper.

\section{References}

[1] M. Kubiak, M. M. ŁApienis, D. Kaczmarczyk, and A. MorawiecSztandera, "Surgery treatment of salivary gland tumors," Otolaryngologia Polska, vol. 62, no. 5, pp. 567-573, 2008.

[2] F. Palluch, M. Lehmann, J. Volz, T. Upile, and H. Sudhoff, "The rapid growth of a pleomorphic adenoma of the parotid gland in the third trimester of pregnancy," Journal of Medical Case Reports, vol. 5, article 141, 2011.

[3] A. Maruyama, T. Tokumaru, and K. Kitamura, "Pleomorphic adenoma presenting with conductive hearing loss in the ear canal: a case report and review of the literature," Journal of Medical Case Reports, vol. 8, article 178, 2014.

[4] K. Markou, I. Karasmanis, K. Vlachtsis, D. Petridis, A. Nikolaou, and V. Vital, "Primary pleomorphic adenoma of the external ear canal. Report of a case and literature review," The American Journal of Otolaryngology-Head and Neck Medicine and Surgery, vol. 29, no. 2, pp. 142-146, 2008.

[5] P. L. Auclair and G. L. Ellis, "Major salivary glands," in Principles and Practice of Surgical Pathology and Cytopathology, S. G. Silverberg, R. A. Delellis, and W. J. Frable, Eds., pp. 1461-1515, Churchill Livingstone, Edinburgh, UK, 3rd edition, 1997.

[6] Y.-L. Kuo, T.-Y. Tu, C.-F. Chang et al., "Extra-major salivary gland pleomorphic adenoma of the head and neck: a 10-year experience and review of the literature," European Archives of Oto-Rhino-Laryngology, vol. 268, no. 7, pp. 1035-1040, 2011. 
[7] S. C. Debnath and A. K. Adhyapok, "Pleomorphic adenoma (benign mixed tumor) of the minor salivary glands of the upper lip," Journal of Maxillofacial and Oral Surgery, vol. 9, no. 2, pp. 205-208, 2010.

[8] C. Saito, T. Kanazawa, T. Yamaguchi, K. Nakamura, and K. Ichimura, "Primary pleomorphic adenoma of the external auditory canal: a case report and review of the literature," Case Reports in Otolaryngology, vol. 2014, Article ID 975151, 4 pages, 2014.

[9] L. S. Ayers, K. Depasquale, F. I. Marlowe, and M. Ghaderi, "Pleomorphic adenoma of the external auditory canal: a case report and review of the literature," Ear, Nose and Throat Journal, vol. 89, no. 3, pp. E1-E3, 2010.

[10] L. D. R. Thompson, B. L. Nelson, and E. L. Barnes, "Ceruminous adenomas: a clinicopathologic study of 41 cases with a review of the literature," The American Journal of Surgical Pathology, vol. 28, no. 3, pp. 308-318, 2004.

[11] C. R. Rabinov, R. F. Canalis, S. Alavi, and E. J. Lee, "Recurrent pleomorphic adenoma of the parotid gland involving the osseous external auditory canal: with a note on the foramen of Huschke," Annals of Otology, Rhinology and Laryngology, vol. 106, no. 7, pp. 589-593, 1997.

[12] S. Chadha, K. K. Pannu, and K. S. Gill, "Pleomorphic adenoma of external auditory canal," Indian Journal of Otolaryngology and Head \& Neck Surgery, vol. 63, pp. 61-63, 2011.

[13] G. W. Hicks, "Tumors arising from the glandular structures of the external auditory canal," Laryngoscope, vol. 93, no. 3, pp. 326-340, 1983.

[14] N. A. Obaidat, K. O. Alsaad, and D. Ghazarian, "Skin adnexal neoplasms-part 2: an approach to tumours of cutaneous sweat glands," Journal of Clinical Pathology, vol. 60, no. 2, pp. 145-159, 2007.

[15] J. B. C. Botha and L. B. Kahn, "Aggressive chondroid syringoma. Report of a case in an unusual location and with local recurrence," Archives of Dermatology, vol. 114, no. 6, pp. 954-955, 1978.

[16] I. Vasileiadis, S. Kapetanakis, A. Petousis, E. Karakostas, and C. Simantirakis, "Rapidly growing chondroid syringoma of the external auditory canal: report of a rare case," Case Reports in Medicine, vol. 2011, Article ID 589680, 3 pages, 2011.

[17] W. M. Mendenhall, C. M. Mendenhall, J. W. Werning, R. S. Malyapa, and N. P. Mendenhall, "Salivary gland pleomorphic adenoma," The American Journal of Clinical Oncology: Cancer Clinical Trials, vol. 31, no. 1, pp. 95-99, 2008. 


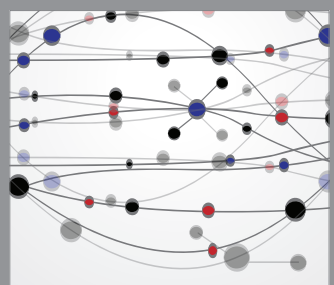

The Scientific World Journal
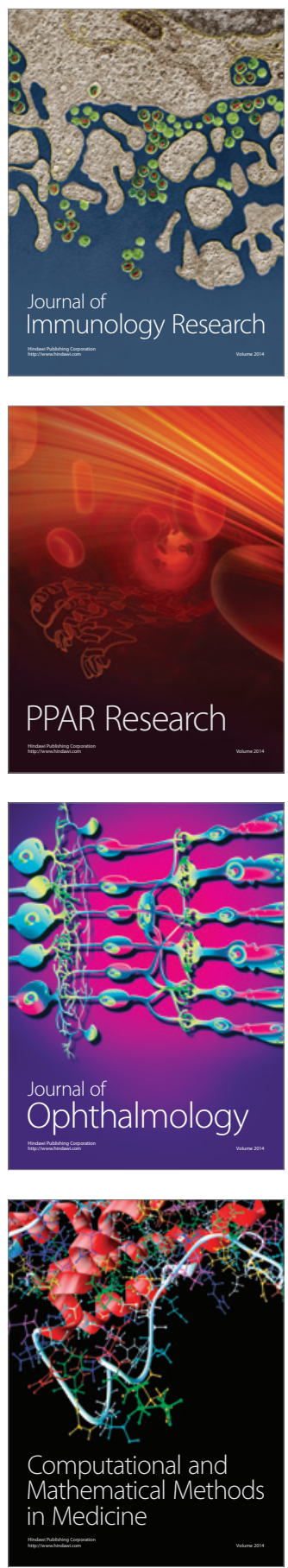

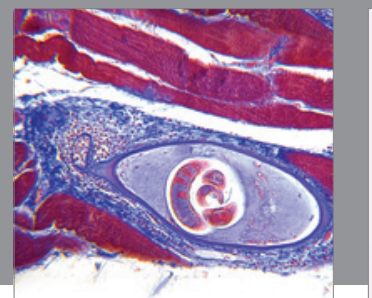

Gastroenterology

Research and Practice
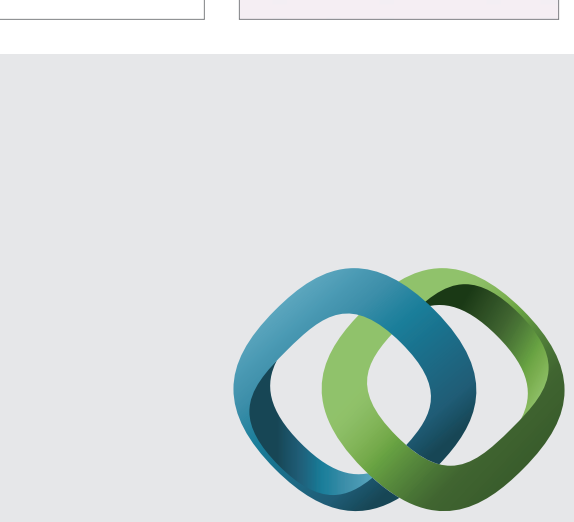

\section{Hindawi}

Submit your manuscripts at

http://www.hindawi.com
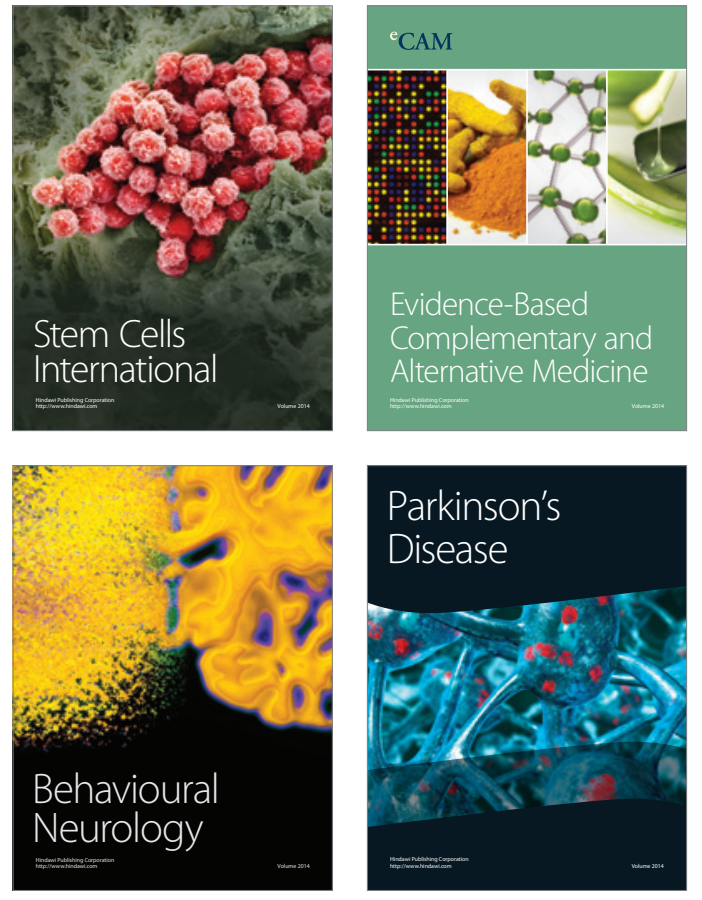
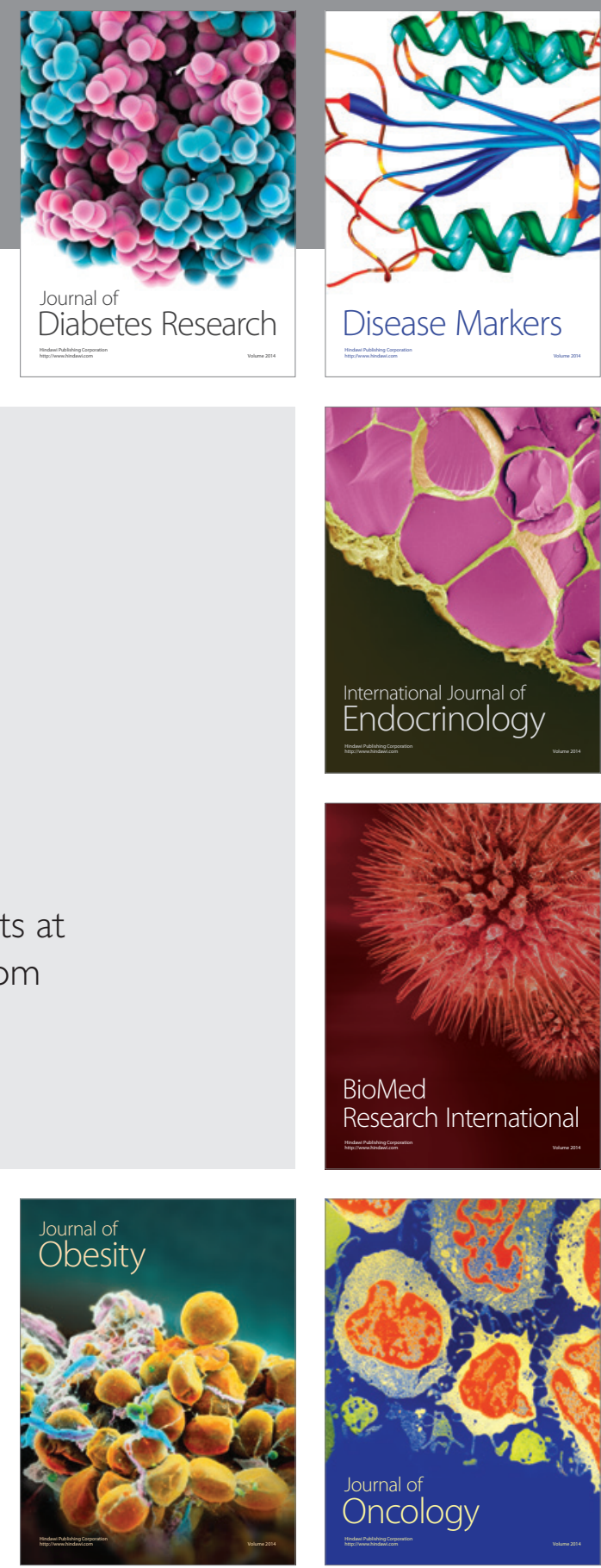

Disease Markers
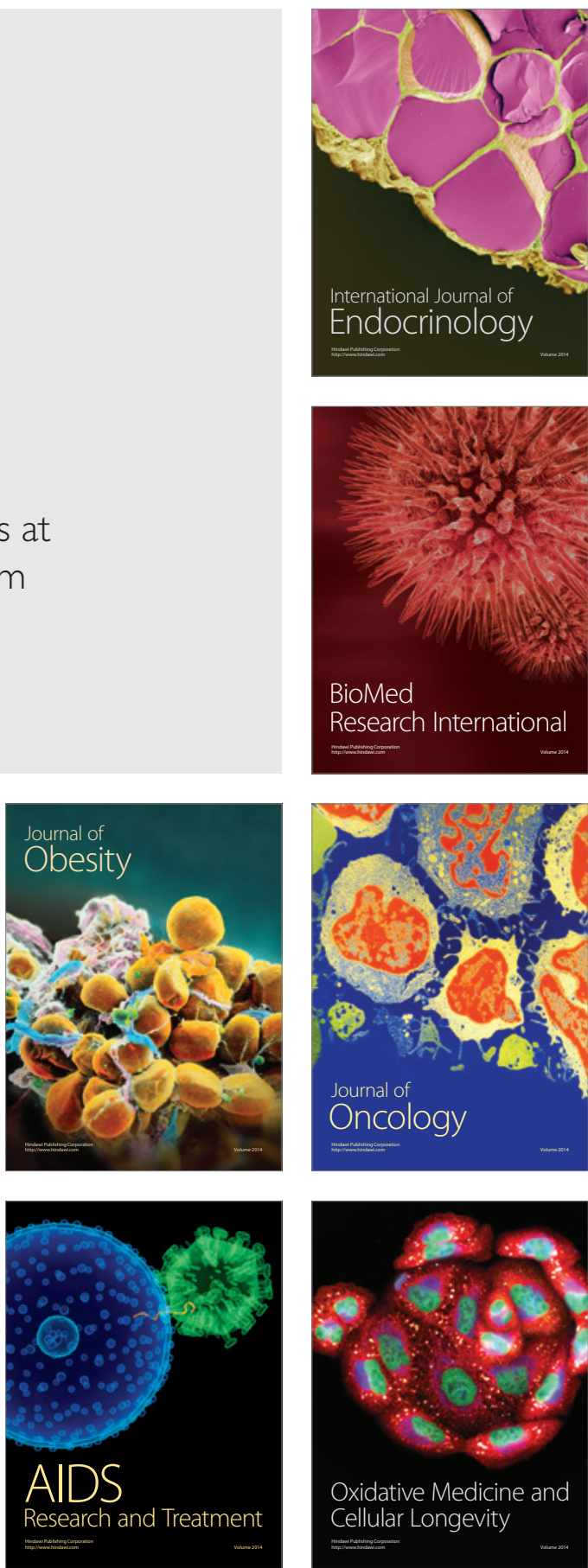